\title{
ANALISIS STABILITAS DINDING PENAHAN TANAH DENGAN PERKUATAN BRONJONG PADA JALAN TOL ULUJAMI - PONDOK RANJI RAMP BINTARO VIADUCT
}

\author{
Maria Febe $^{(1)}$, Imam Hariadi Sasongko ${ }^{(2)}$ \\ 1,2 Jurusan Teknik Sipil-PNJ, Jl. Prof. Dr. G. A. Siwabessy, Kampus Baru UI Depok 16424, Telp. +6221 \\ 7270036, Fax. (021) 7270034, email : \\ mfebe@outlook.com,imamhariadi@ymail.com
}

\begin{abstract}
ABSTRAK
Pada Jalan Tol Ulujami - Pondok Ranji STA 03+150 terdapat sebuah jembatan yang opritnya mengalami penurunan yang menyebabkan ketidaknyamanan saat melintas di bahu jalannya. Penyebab penurunan tersebut diduga akibat adanya pergerakan struktur tanah bawah jalan sehingga menimbulkan terjadinya ketidakstabilan bangunan diatasnya. Tujuan studi adalah untuk mengetahui nilai faktor keamanan dinding penahan tanah dengan perkuatan bronjong terhadap kelongsoran, stabilitas geser, guling, dan daya dukung tanah, serta penurunan. Perhitungan tekanan tanah dinding ini menggunakan Teori Rankine. Untuk perhitungan stabilitas terhadap daya dukung tanah menggunakan persamaan Terzaghi. Perhitungan stabilitas dinding terhadap kelongsoran menggunakan metode Fellenius dan perangkat lunak Plaxis 8.6. Penurunan yang dihitung adalah penurunan konsolidasi primer dan sekunder. Hasil perhitungan stabilitas pada dinding penahan gravitasi didapatkan bahwa dimensi dinding tersebut tidak aman terhadap geser dan guling yaitu $\mathrm{Fgl}=0,110 \leq 1,5$ dan $\mathrm{Fgs}=0,205 \leq 1,5$. Serta penurunan yang terjadi sebesar $57,8 \mathrm{~cm}$ selama 62,704 tahun. Dari hasil perhitungan faktor keamanan stabilitas guling dan geser pada dinding penahan gravitasi tersebut, maka direncanakan perbesaran dimensi dinding agar aman terhadap geser dan guling. Didapati faktor keamanannya terhadap geser dan guling menjadi $\mathrm{Fgs}=2,225 \geq 1,5$ dan $\mathrm{Fgl}=$ $1,740 \geq 1,5$.
\end{abstract}

Kata kunci: dinding penahan tanah, bronjong, stabilitas dinding penahan tanah

\section{ABSTRACT}

Bridge at STA 03+150 Ulujami - Pondok Ranji toll road has an approach settlement reduces its service and traffic may disturbed significantly. Settlement probably triggered by soil structure movement at the bottom of the road. The instability occurred and finally structure above damaged. The aim of the study was to calculate the safety factor of retaining wall strengthened with gabion against sliding, shear, overturning, and bearing capacity failure as well as its settlement. The calculation of safety factor against shear and overtuning conducted using Rankine Theory, while bearing capacity calculation done by uses Terzaghi. Calculations of sliding using Fellenius method and Plaxis 8.6 software. The writer also calculate settlement, both at primary and secondary consolidations. The results of stability calculation of gravity wall were as follows: safety factor against overtuning was 0,110 and shear 0,205 respectively, while settlement was $57,8 \mathrm{~cm}$ for 62,704 years. After the calculation mention above, in which all of the aspects calculated was not safe, the gravity wall then be redesigned as seen in the figure and the stability increase become 2,225 for shear 1,740 for overturning stability respectively. Using minimum allowable safety factor as 1,5 for all calculations, the gravity wall is now safe.

Keywords: retaining walls, gabion, stability of retaining wall 


\section{PENDAHULUAN}

Oprit jembatan Jalan Tol Ulujami - Pondok Ranji STA 03+150 setinggi 7 m yang mengalami penurunan yang mengakibat ketidaknyamanan. Penurunan tersebut diduga akibat pergerakan struktur tanah bawah jalan sehingga menimbulkan ketidakstabilan bangunan diatasnya. Tanah pada oprit jembatan ini ditopang oleh dinding penahan tanah dengan perkuatan bronjong.

Tujuan dari studi ini adalah :

1. Mengetahui nilai faktor keamanan dinding penahan tanah dengan perkuatan bronjong terhadap kelongsoran pada setiap tingkatannya.

2. Mengetahui nilai faktor keamanan dinding penahan tanah dengan perkuatan bronjong terhadap stabilitas geser, guling, dan daya dukung tanah.

3. Mengetahui besarnya penurunan pada bahu jalan yang menimbulkan ketidaknyamanan untuk pengendara.

Untuk mencapai tujuan tersebut maka dasar teorinya, sebagai berikut :

1. Dinding Penahan

Dinding penahan tanah merupakan konstruksi untuk menahan tekanan tanah lateral. Tipe dinding penahan yang dapat digunakan adalah: dinding bronjong, dinding krib, dinding tanah bertulang, dinding gravitasi, dinding kantilever, dinding counterfort, dinding berangkur (tie - back), dan dinding tiang - tiang.

2. Dinding Penahan Bronjong (Gabion)

Bronjong kawat adalah anyaman kawat baja berlapis seng yang diisi batu untuk pencegah erosi, dipasang pada tebing, tepi sungai. Lihat Gambar 1.

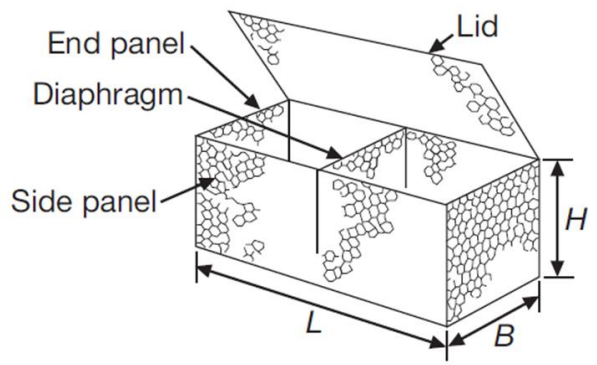

Gambar 1. Bronjong (gabion) bersekat untuk 2 ruang yang sudah siap diisi batu.

3. Stabilitas Lereng

Pada permukaan tanah yang miring, gaya gravitasi akan mendorong tanah ke bawah. Analisis stabilitas dilakukan pada permukaan tanah yang miring untuk menghindari kelongsoran lereng. Faktor yang mempengaruhi perhitungan stabilitas lereng adalah kondisi tanah berlapis, kuat geser tanah anisotropis, aliran air dalam tanah, dll. Fellenius (1936) beranggapan gaya-gaya yang bekerja pada sisi kanankiri dari sembarang irisan mempunyai resultan nol pada arah tegak lurus bidang longsor. Metode Fellenius menghasilkan faktor aman yang lebih rendah dari cara perhitungan yang lebih teliti. Walaupun analisis ditinjau dalam tinjauan tegangan total, kesalahan analisis masih merupakan fungsi dari faktor aman dan sudut pusat lingkaran. 
4. Tekanan Tanah Lateral

Tekanan Tanah lateral adalah tekanan dari tanah ke suatu struktur atau dinding penahan tanah. Jenis tekanan yang terdapat pada dinding penahan tanah, yaitu:

1. Tekanan Tanah Aktif

Tekanan tanah aktif adalah tekanan yang menyebabkan dinding/tembok penahan tanah bergerak diakibatkan oleh dorongan dari tanah urugan dibelakangnya.

2. Tekanan Tanah Pasif

Tekanan tanah pasif adalah tekanan yang diberikan pada dinding penahan tanah kearah tanah urugan dengan kata lain, tekanan tanah pasif merupakan perlawanan dari tekanan tanah aktif.

3. Stabilitas Dinding Penahan Tanah

Faktor keamanan dinding penahan tanah terhadap geser dan guling harus mencukupi. Tekanan yang terjadi pada tanah dasar pondasi tidak boleh melebihi daya dukung tanah yang diizinkan. Stabilitas lereng secara keseluruhan harus memenuhi syarat. Faktor aman terhadap penggeseran dasar pondasi $\left(F_{g s}\right)$ minimum, diambil 1,5. Bowles (1997) menyarankan $F_{g s} \geq 1,5$ untuk tanah dasar granuler dan $F_{g s} \geq 2$ untuk tanah dasar kohesif. Faktor aman terhadap penggulingan $\left(F_{g l}\right)$ bergantung pada jenis tanah $F_{g l} \geq 1,5$ untuk tanah dasar granuler dan $F_{g l} \geq 2$ untuk tanah dasar kohesif.

Faktor daya dukung tanah $N_{c}$ dan $N_{q}$ merupakan faktor daya dukung tanah akibat pengaruh kohesi dan beban terbagi rata yang keduanya merupakan fungsi dari sudut gesek dalam $(\varphi)$. Syarat minimum faktor aman $(F)$ terhadap keruntuhan tanah diambil sama dengan 3. (Hardiyatmo, 2014)

5. Penurunan

Penurunan adalah gerakan titik tertentu pada bangunan terhadap titik referensi yang tetap. Ada tiga komponen penurunan pada tanah berbutir halus yang jenuh, yaitu penurunan segera, penurunan konsolidasi primer, dan penurunan konsolidasi sekunder.

\section{METODE PENELITIAN}

Metode studi yang dilakukan adalah perhitungan tekanan tanah lateral menggunakan Teori Rankine untuk mendapatkan faktor keamanan stabilitas dinding penahan tanah terhadap geser, guling, dan daya dukung tanah. Untuk perhitungan stabilitas daya dukung tanah dihitung dengan menggunakan persamaan Terzaghi. Kemudian, dilakukan perhitungan stabilitas lereng dengan menggunakan metode Fellenius dan perangkat lunak Plaxis 8.6 untuk mendapatkan nilai faktor keamanan yang lebih teliti serta untuk permodelannya, penulis menggunakan perangkat lunak AUTOCAD 2013. Perhitungan penurunan dilakukan pada penurunan konsolidasi primer dan sekunder. 


\section{HASIL DAN PEMBAHASAN}

Perhitungan stabilitas dinding penahan tanah dibagi menjadi tiga, seperti pada Gambar
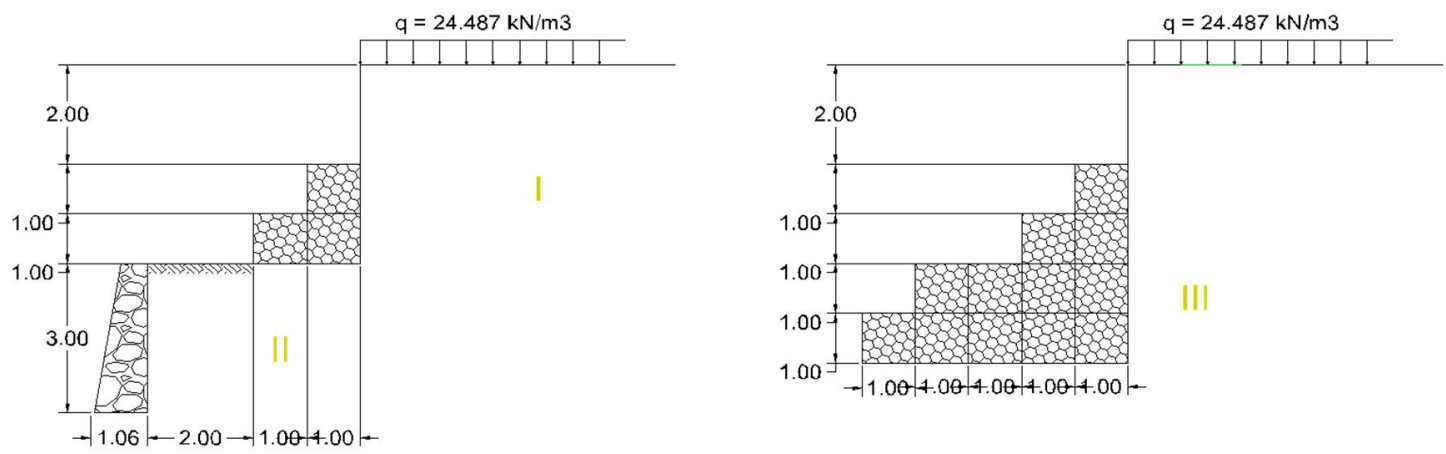

Gambar 2. Jenis dinding penahan tanah I, II, III

Tabel 1. Hasil Perhitungan Momen Akibat Gaya Vertikal

\begin{tabular}{cccc}
\hline No. & Berat $(\mathrm{W}) \mathrm{kN} / \mathrm{m}$ & Jarak $(\mathrm{x})$ & Momen $(\mathrm{Mw}) \mathrm{kN}$ \\
\hline 1 & 27 & 1.5 & 40.5 \\
2 & 27 & 0.5 & 13.5 \\
3 & 27 & 1.5 & 40.5 \\
TOTAL & 81 & & 94.5 \\
\hline
\end{tabular}

Tabel 2. Gaya - Gaya Horizontal Dan Perhitungan Momen

\begin{tabular}{cccc}
\hline No. & Tekanan Tanah Aktif $(\mathrm{Pa}) \mathrm{kN}$ & Jarak $(\mathrm{l})$ & Momen $(\mathrm{Ma}) \mathrm{kN}$ \\
\hline 1 & 23.114 & 3.000 & 69.343 \\
2 & 15.736 & 2.667 & 41.964 \\
3 & -30.228 & 3.000 & -90.684 \\
4 & 9.413 & 1.500 & 14.119 \\
5 & 12.817 & 1.500 & 19.225 \\
6 & 2.808 & 1.333 & 3.745 \\
7 & -11.160 & 1.500 & -16.740 \\
8 & 9.201 & 0.500 & 4.601 \\
9 & 12.529 & 0.500 & 6.265 \\
10 & 5.491 & 0.500 & 2.746 \\
11 & 2.524 & 0.333 & 0.841 \\
12 & -13.486 & 0.500 & -6.743 \\
TOTAL & 38.759 & & 48.680 \\
\hline
\end{tabular}

Sebagai contoh, perhitungan stabilitas dinding penahan I dapat dilihat pada Tabel 1 dan Tabel 2 dengan rumus seperti berikut.

$W=p . l . \gamma$

$\mathrm{x}=$ Jarak beban terhadap ujung dinding penahan (di titik O)

$M_{w}=W_{1} \cdot x_{1}$

$P_{a}=\gamma h K_{a}-2 c \sqrt{K_{a}}$

$K_{a}=\tan ^{2}\left(45^{\circ}-\frac{\varphi}{2}\right)$

$1=$ Jarak lengan terhadap titik O

Tahanan geser pada dinding sepanjang $B=2 \mathrm{~m}$, dihitung dengan menganggap dasar dinding sangat kasar. Sehingga sudut geser $\delta_{b}=\varphi_{3}$ dan adhesi $c_{d}=c_{3}$. 
Untuk tanah dengan $\mathrm{c}-\varphi(\varphi>0$, dan $\mathrm{c}>0)$, maka :

$\sum R_{h}=c_{d} \cdot B+W \tan \delta_{b}=11.2+81 \tan 27^{\circ}=63,272 \mathrm{kN} / \mathrm{m}$

$F_{g s}=\frac{\sum R_{h}}{\sum P_{h}}=\frac{63,272}{38,760}=1,632 \geq 1,5 \rightarrow($ aman $)$

Tekanan tanah lateral yang diakibatkan oleh tanah dibelakang dinding penahan, cenderung menggulingkan dinding, dengan pusat rotasi terletak pada ujung kaki depan dinding penahan tanah.

$F_{g l}=\frac{\sum M_{w}}{\sum M_{a}}=\frac{94,5}{48,680}=1,941 \geq 1,5 \rightarrow($ aman $)$

Dalam hal ini, penulis akan menggunakan persamaan Terzaghi pada perhitungan, dengan mengganggap dinding penahan tanah terletak pada permukaan. Perhitungan juga dilakukan berdasarkan baris dinding karena memiliki berat yang berbeda.

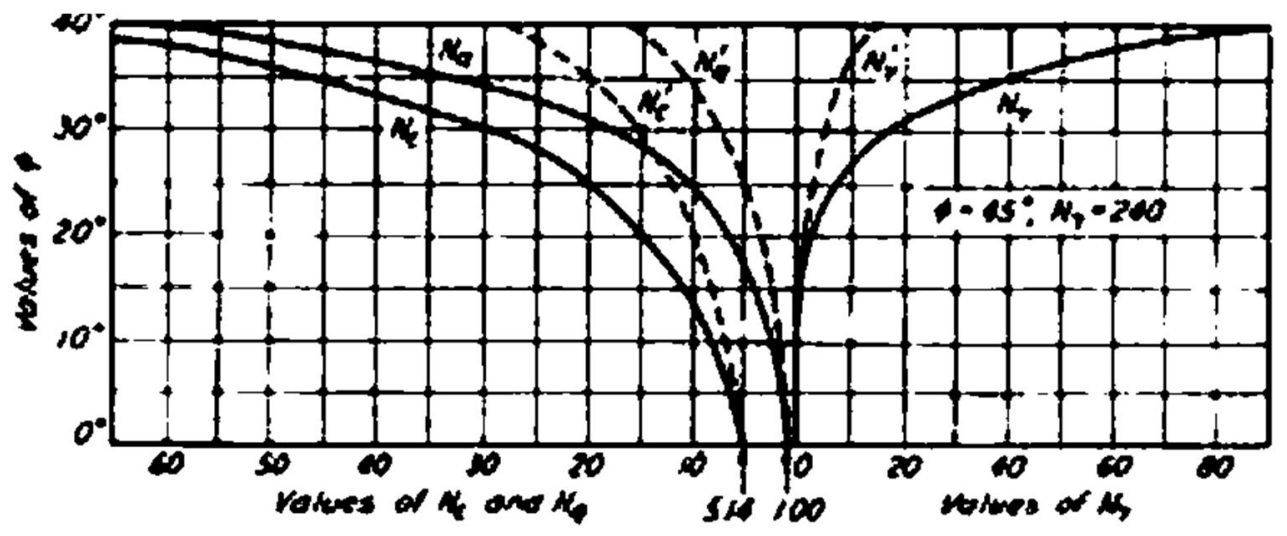

Gambar 3. Menentukan nilai $\mathrm{N}_{\mathrm{c}}, \mathrm{N}_{\mathrm{q}}, \mathrm{N}_{\mathrm{y}}$ untuk $\varphi=27^{\circ}$

Berdasarkan Gambar 3, untuk $\varphi=27^{\circ}$, maka didapatkan :

$$
\begin{aligned}
& \mathrm{N}_{\mathrm{c}}=22,5 ; \mathrm{N}_{\mathrm{q}}=12,5 ; \mathrm{N}_{\mathrm{y}}=10 \\
& q_{u}=c N_{c}+D_{f} \gamma N_{q}+0,5 \gamma B N_{y}=11 \cdot 22,5+0.13,435 \cdot 12,5+0,5 \cdot 13,435 \cdot 1 \cdot 10= \\
& 314,675 \mathrm{kN} / \mathrm{m}^{2} \\
& q_{u n}=q_{u}-\gamma D_{f}=314,675-13,435.0=314,675 \mathrm{kN} / \mathrm{m}^{2} \\
& q_{1}=\frac{\left(W_{1}+W_{3}\right)}{B}=\frac{(27+2)}{1}=54 \mathrm{kN} / \mathrm{m}^{2} \\
& q_{n 1}=q-\gamma D_{f}=54-13,435 \cdot 0=54 \mathrm{kN} / \mathrm{m}^{2} \\
& q_{2}=\frac{\left(W_{2}\right)}{B}=\frac{(27)}{1}=27 \mathrm{kN} / \mathrm{m}^{2} \\
& q_{n 2}=q-\gamma D_{f}=27-13,435 \cdot 0=27 \mathrm{kN} / \mathrm{m}^{2} \\
& F_{1}=\frac{q_{u n}}{q_{n 1}}=\frac{314,67}{54}=5,827 \geq 3 \rightarrow(\text { aman }) \\
& F_{2}=\frac{q_{u n}}{q_{n 2}}=\frac{314,67}{27} \stackrel{5}{=} 11,655 \geq 3 \rightarrow(\text { aman })
\end{aligned}
$$

Selanjutnya, perhitungan stabilitas dinding penahan II dan III dihitung sama seperti perhitungan stabilitas dinding penahan I. Didapati hasil perhitungan stabilitas dinding penahan II faktor keamanan terhadap geser $F_{g s}=0,205 \leq 1,5 \rightarrow$ (tidak aman), 
faktor keamanan terhadap guling $F_{g l}=0,110 \leq 1,5 \rightarrow$ (tidak aman), dan faktor keamanan terhadap daya dukung tanah $F=6,694 \geq 3$ (aman).

Sedangkan hasil perhitungan stabilitas dinding penahan III faktor kemanan terhadap gesernya $F_{g s}=2,886 \geq 1,5 \rightarrow$ (aman), faktor keamanan terhadap guling $F_{g l}=$ $6,228 \geq 1,5 \rightarrow($ aman $)$, dan faktor keamanan terhadap daya dukung tanah $F_{1}=$ $3,637 \geq 3$ (aman), $F_{2}=4,850 \geq 3$ (aman), $F_{3}=7,275 \geq 3$ (aman), $F_{4}=7,275 \geq$ 3 (aman), $F_{5}=14,549 \geq 3$ (aman).

Perhitungan stabilitas lereng yang penulis lakukan menggunakan 5 titik iterasi yang berbeda - beda ukuran jari - jarinya. Perhitungan dilakukan tanpa pengaruh tekanan air pori. Dari kelima perhitungan tersebut di dapati faktor keamanan yang paling kritis $=\frac{\sum c \cdot L+\sum W_{t} \cos \alpha \cdot \tan \varphi}{\sum W_{t} \sin \alpha}=\frac{22.2,9+66,93 \cdot \tan 19,8}{59,42}=1,48$.

Dengan bentuk iterasi seperti pada Gambar 4 dan perhitungannya pada Tabel 3.

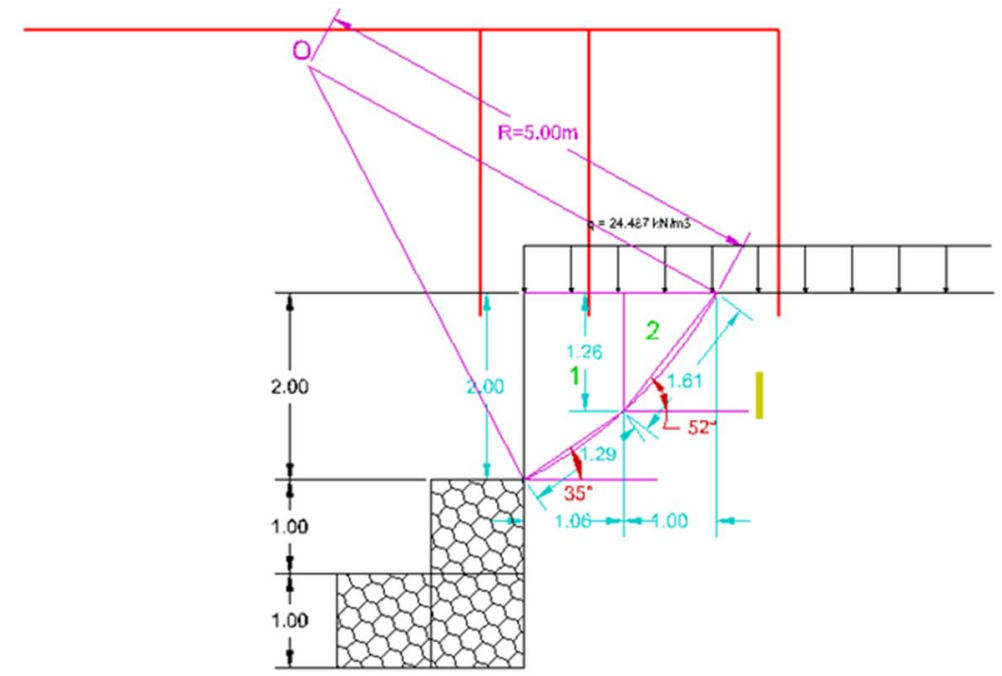

Gambar 4. Iterasi dengan nilai faktor keamanan paling kritis

Tabel 3. Perhitungan stabilitas lereng iterasi I

\begin{tabular}{cccccccc}
\hline No. & $\mathrm{L}(\mathrm{m})$ & $\mathrm{h}(\mathrm{m})$ & $\mathrm{x}(\mathrm{m})$ & Luas $\left(\mathrm{m}^{2}\right)$ & $\alpha^{\circ}$ & $\sin \alpha$ & $\cos \alpha$ \\
\hline 1 & 1.29 & 2.00 & 1.06 & 1.73 & 35.00 & 0.57 & 0.82 \\
2 & 1.61 & 1.26 & 1.00 & 0.63 & 52.00 & 0.79 & 0.62 \\
Total & 2.9 & & & & \\
No. & Wt (Luas . $\gamma)$ & Wt . $\sin \alpha$ & Wt . $\cos \alpha$ \\
1 & 55.27 & 31.70 & 45.27 & & \\
2 & 35.17 & 27.72 & 21.66 & & \\
Total & & 59.42 & \multicolumn{2}{c}{66.93} \\
\hline
\end{tabular}

Selanjutnya perhitungan menggunakan perangkat lunak Plaxis 8.6, didapati nilai faktor keamanan paling kritis sebesar $\mathrm{F}=1,13$ dan gambar deformasi lereng dapat dilihat pada Gambar 5. Penurunan tanah pada jalan tol tersebut dihitung berdasarkan Gambar 6. 


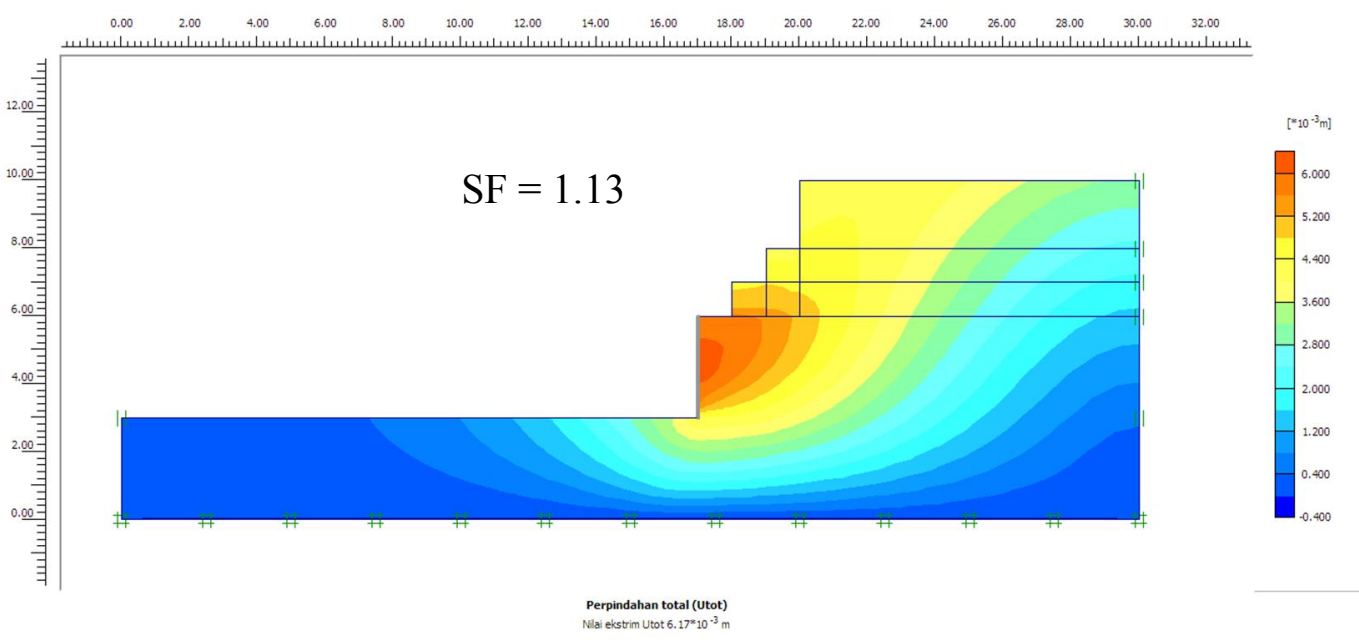

Gambar 5. Deformasi total lereng dengan dinding penahan bronjong dan pasangan batu kali

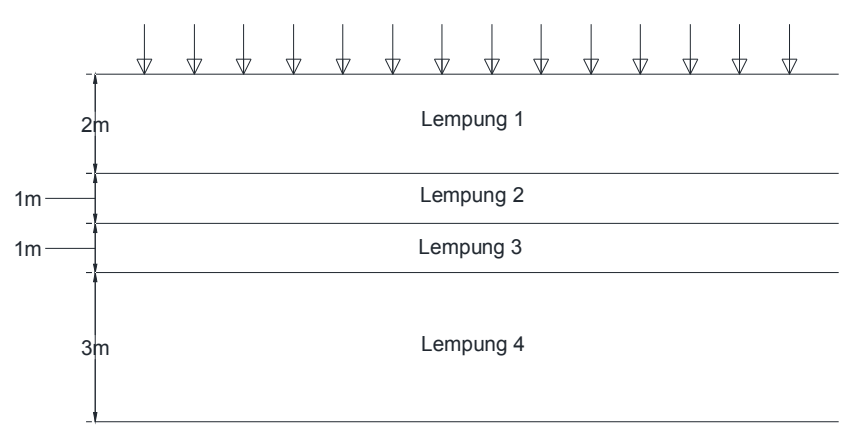

\begin{tabular}{ccccc}
\hline & $\gamma$ & w & Gs & LL \\
\hline Lapis & $\left(\mathrm{gr}^{\prime} / \mathrm{cm}^{3}\right)$ & $(\%)$ & $(\%)$ & $(\%)$ \\
\hline 1 & 1.7 & 45.8 & 2.65 & 96 \\
\hline 2 & 1.49 & 54.7 & 2.66 & 86 \\
\hline 3 & 1.37 & 63 & 2.68 & 76 \\
\hline 4 & 1.73 & 39.8 & 2.61 & 80 \\
\hline
\end{tabular}

Gambar 6. Penurunan yang ditinjau

Dengan parameter tanah seperti pada Tabel 4. Maka didapati penurunan konsolidasi primer total seperti pada Tabel 5. Dengan rumus seperti berikut:

$\Delta e=C c \log \frac{p_{o}^{\prime}+\Delta p}{p_{o}^{\prime}}$

$S_{c}=\frac{\Delta e}{1+e} H$

Tabel 4. Perhitungan parameter tanah

\begin{tabular}{ccccccc}
\hline Lapis & $\Gamma \mathrm{d}$ & $\mathrm{e}$ & $\mathrm{Cc}$ & $\mathrm{H}$ & $\gamma \mathrm{sat}$ & $\gamma \mathrm{sat} \mathrm{kN} / \mathrm{m} 3$ \\
\hline 1 & 1.166 & 1.273 & 0.602 & 2 & 1.726 & 17.260 \\
2 & 0.963 & 1.762 & 0.532 & 1 & 1.601 & 16.011 \\
3 & 0.840 & 2.189 & 0.462 & 1 & 1.527 & 15.269 \\
4 & 1.237 & 1.109 & 0.49 & 3 & 1.763 & 17.634 \\
\hline
\end{tabular}

Tabel 5. Perhitungan konsolidasi primer

\begin{tabular}{cccc}
\hline $\begin{array}{c}\mathrm{po}^{\prime} \\
\mathrm{kN} / \mathrm{m} 2\end{array}$ & $\Delta \mathrm{e}$ & $\begin{array}{c}\mathrm{Sc} \\
\mathrm{m}\end{array}$ & $\begin{array}{c}\mathrm{Sc} \\
\mathrm{cm}\end{array}$ \\
\hline 17.260 & 0.231 & 0.203 & 20.321 \\
42.525 & 0.105 & 0.038 & 3.805 \\
58.165 & 0.070 & 0.022 & 2.211 \\
92.249 & 0.050 & 0.071 & 7.126 \\
& & & 33.462 \\
\hline
\end{tabular}


Untuk menghitung waktu penurunan konsolidasi $90 \%\left(\mathrm{U}=90 \% ; \mathrm{T}_{\mathrm{v}}=0,848\right)$. Karena drainasi satu arah, maka $\mathrm{H}_{\mathrm{t}}=\mathrm{H}=7 \mathrm{~m}$. Maka waktu yang dibutuhkan untuk penurunan $90 \%$ adalah :

$$
\begin{gathered}
\mathrm{m}_{\mathrm{v}} \quad=\Delta \mathrm{e} / \Delta \mathrm{p}(1+\mathrm{e})=0,231 / 24,487(1+1,273)=0,004 \mathrm{~m}^{2} / \mathrm{kN} \\
\gamma_{\mathrm{w}}=10 \mathrm{kN} / \mathrm{m}^{3} \\
\text { Maka }: C_{v}=\frac{k}{m_{v} \gamma_{w}}=\frac{10^{-9} \mathrm{~m} / \mathrm{dt}}{\frac{0,004 \mathrm{~m}^{2}}{k N} \times 10 \mathrm{kN} / \mathrm{m}^{3}}=2,5 \times 10^{-8} \mathrm{~m}^{2} / \mathrm{dt} \\
T_{v}=\frac{C_{v} t}{H^{2}} \\
t=\frac{0,848 \times 70^{2} 0}{2,5 \times 10^{-4} \times 365 \times 24 \times 60 \times 60}=52,704 \text { tahu } n
\end{gathered}
$$

Jadi, waktu yang dibutuhkan utnuk penurunan sebesar 90\% adalah 52,704 tahun. selanjutnya, perhitungan penurunan konsolidasi sekunder dengan $\Delta \mathrm{t}$ di asumsikan selama 10 tahun, dapat dilihat pada Tabel 6 dengan $S_{s}=C_{a}^{\prime} H \log \frac{t_{1}+\Delta t}{t_{1}}$.

Tabel 6. Perhitungan penurunan konsolidasi sekunder

\begin{tabular}{ccccc}
\hline Lapis & $\mathrm{w}$ & $\mathrm{Ca}^{\prime}$ & $\mathrm{H}$ & $\mathrm{Ss}$ \\
\hline 1 & 45.8 & 0.45 & 2 & 0.068 \\
2 & 54.7 & 0.55 & 1 & 0.041 \\
3 & 63 & 0.63 & 1 & 0.048 \\
4 & 39.8 & 0.38 & 3 & 0.086 \\
& & & Total & 0.243 \\
\hline
\end{tabular}

Jadi, penurunan total konsolidasi sekunder sebesar $0,243 \mathrm{~m}$ atau $24,3 \mathrm{~cm}$ yang terjadi setelah penurunan konsolidasi primer terhenti. Penurunan total $=\mathrm{S}_{\mathrm{c}}+\mathrm{S}_{\mathrm{s}}=33,5+24,3=$ $57,8 \mathrm{~cm}$ yang terjadi selama 62,704 tahun.

Dari hasil perhitungan stabilitas dinding penahan tanah II, di dapatkan faktor keamanan terhadap geser dan guling yang tidak aman. Maka dari itu, sebagai solusinya penulis merencanakan perbesaran dimensi dinding penahan tanah II agar mendapat faktor keamanan terhadap geser dan guling lebih besar dari 1,5.

Dengan perbesaran dimensi dinding penahan II seperti pada Gambar 7, didapati nilai faktor keamanan terhadap geser sebesar $F_{g s}=2,225 \geq 1,5 \rightarrow$ (aman), faktor keamanan terhadap guling sebesar $F_{g l}=1,740 \geq 1,5 \rightarrow$ (aman), dan faktor keamanan terhadap daya dukung tanah sebesar $F_{g l}=1,740 \geq 1,5 \rightarrow$ (aman). Untuk faktor keamanan stabilitas lereng di dapati sebesar 1,67. 


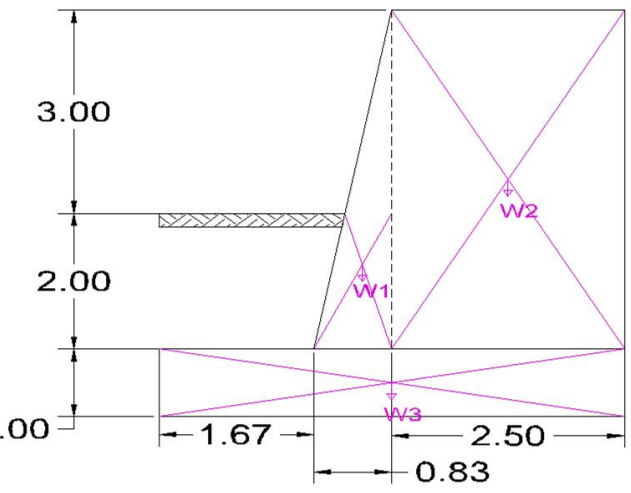

Gambar 7. Rencana Perbesaran Dimensi Dinding Penahan II

Tabel 7. Hasil Perhitungan Seluruhnya

\begin{tabular}{lllllllll}
\hline No. & Stabilitas & \multicolumn{2}{l}{ Dinding penahan } \\
I & $\begin{array}{l}\text { Dinding } \\
\text { penahan } \\
\text { II }\end{array}$ & Dinding penahan III & & \\
\hline 1 & Geser & 1.632 & & 0.205 & 2.886 & & & \\
2 & $\begin{array}{l}\text { Guling } \\
\text { Daya } \\
\text { dukung } \\
\text { tanah }\end{array}$ & 1.941 & 0.110 & 6.228 & & & & \\
\hline
\end{tabular}

Tabel 8. Hasil Perhitungan Setelah Perbesaran Dimensi

\begin{tabular}{ccc}
\hline No. & Stabilitas & Dinding penahan diperbesar \\
\hline 1 & Geser & 2.225 \\
2 & Guling & 1.740 \\
3 & Daya dukung tanah & 20.039 \\
4 & Lereng & 1.67 \\
\hline
\end{tabular}

\section{KESIMPULAN}

Dari hasil analisis dinding penahan tanah pada Jalan Tol Ulujami - Pondok Ranji Ramp Bintaro Viaduct, maka di dapat:

1. Nilai faktor keamanan dinding penahan tanah dengan perkuatan bronjong terhadap kelongsoran pada setiap tingkatannya. Sebesar :

a. Dengan metode Fellenius faktor keamanan paling kritis didapati sebesar 1,48

b. Dengan perangkat lunak Plaxis 8.6 faktor keamanan paling kritis didapati sebesar 1,13 pada lereng dengan dinding penahan bronjong dan pasangan.

2. Nilai faktor keamanan dinding penahan tanah dengan perkuatan bronjong terhadap stabilitas geser, guling, dan daya dukung tanah dapat dilihat pada Tabel 7.

3. Penurunan total $=\mathrm{S}_{\mathrm{c}}+\mathrm{S}_{\mathrm{s}}=33,5+24,3=57,8 \mathrm{~cm}$ yang terjadi selama 62,704 tahun. Hal ini menyebabkan ketidaknyamanan pengendara saat melintasi bahu jalan tol. 
Dari kesimpulan - kesimpulan yang sudah dijabarkan sebelumnya, maka penulis menyarankan:

1. Perbesaran dinding penahan 2. Dari dimensi yang sudah diperbesar tersebut, di dapati nilai - nilai stabilitas seperti pada Tabel 8. Dengan dimensi ini, nilai faktor keamanan stabilitas geser dan gulingnya sudah memenuhi syarat, yaitu melebih 1,5.

2. Dapat melakukan pemeliharaan rutin untuk mengatasi penurunan yang terjadi agar tetap terjaga kenyaman pengguna jalan tol saat melintasi bahu jalan.

\section{DAFTAR PUSTAKA}

[1] Badan Standarisasi Nasional (1999), SNI 03 - 0090 - 1999 Bronjong Kawat. Jakarta, Badan Standarisasi Nasional.

[2] Badan Standarisasi Nasional (2005), RSNI - T - 02 - 2005 Pembebanan untuk Jembatan, Jakarta, Badan Standarisasi Nasional.

[3] Brinkgreve, R.B.J (2007), PLAXIS 2D - Versi 8. Belanda, Delft University of Technology and Plaxis b.v.

[4] Das, Braja M. (1998), Mekanika Tanah (Prinsip - prinsip Rekayasa Geoteknis) Jilid 1. Terjemahan oleh Noor Endah dan Indrasurya B. Mochtar. Jakarta, Erlangga.

[5] Djarwanti, N. (2008), Komparasi Koefisien Permeabilitas (k) pada Tanah Kohesif, Jurnal Penelitian Media Teknik Sipil, 8(1), 21 - 24. http://puslit2.petra.ac.id/ejurnal/index.php/mts/article/view/17714

[6] Global Synthetics (2015), LinkTM Gabions and Mattresses Design Booklet, (Online), (www.globalsynthetics.com.au), diakses 10 April 2018.

[7] Hardiyatmo, Hary Christady (2002), Mekanika Tanah 2 (Edisi Kedua), Yogyakarta, Beta Offset.

[8] Hardiyatmo, Hary Christady (2009), Pemeliharaan Jalan Raya Perkerasan Drainase Longsoran, Yogyakarta, Gadjah Mada University Press.

[9] Hardiyatmo, Hary Christady (2014), Analisis dan Perancangan Fondasi 1 (Edisi Ketiga), Yogyakarta, Gadjah Mada University Press.

[10] Indrawahyuni, H, Munawir, As'ad, \& Damayanti, I. (2009), Pengaruh Variasi Kepadatan pada Permodelan Fisik Menggunakan Tanah Pasir Berlempung Terhadap Stabilitas Lereng, Rekayasa Sipil, 3(3), 192 - 208. http://rekayasasipil.ub.ac.id/index.php/rs/article/view/151

[11] KH, Sunggono (1984), Mekanika Tanah, Bandung, Nova.

[12] Pangemanan, V.G.M. (2014), Analisis Kestabilan Lereng dengan Metode Fellenius (Studi Kasus : Kawasan Citraland), Jurnal Sipil Statik, 2(1), 37 - 46.

[13] Ramli, M, Karasu, T.J.r., \& Dawood, E.T. (2013), The Stability of Gabion Walls for Earth Retaining Structures, Alexandria Engineering Journal, 52, 705 - 710.

[14] Setiawan, Hendra (2011), Perbandingan Penggunaan Dinding Penahan Tanah Tipe Kantilever dan Gravitasi Dengan Variasi Ketinggian Lereng, Infrastruktur Jurnal Teknik Sipil, 1(2), 88 - 95.

[15] Zain, M.H, Suryo, E.A, \& Munawir, As'ad (2015), Analisis Stabilitas Lereng Embung Dengan Menggunakan Kombinasi Dinding Penahan Kantilever dan Geotekstil Dengan Bantuan Perangkat Lunak, Jurnal Mahasiswa Jurusan Teknik Sipil, $\quad 1(2), \quad 654 \quad 666$. http://sipil.studentjournal.ub.ac.id/index.php/jmts/article/view/256 